\title{
Calcificación mamaria benigna como secuela de una válvula de derivación ventrículo-peritoneal
}

\section{Benign Breast Calcification as a Sequela of the Ventricular-peritoneal Shunt Valve}

Ivelís M. Sarachi ${ }^{1} \quad$ María del R. Cepedal ${ }^{1}$

${ }^{1}$ Centro Diagnóstico Mon, La Plata, Buenos Aires, Argentina Rev Argent Radiol 2018;82:187-189.

Estimados Editores,

Las calcificaciones mamarias son un hallazgo frecuente en el examen mamográfico, las cuales aumentan con la edad de la paciente. En su mayoría son de origen benigno y no requieren
Address for correspondence Ivelís M. Sarachi, MD, Centro Diagnóstico Mon, La Plata, Calle 8 número 1615, La Plata, CP 1900 Buenos Aires, Argentina (e-mail: ivelis.sarachi@gmail.com).

de incidencias adicionales. Algunas de ellas son infrecuentes, hecho que hace necesario realizar incidencias adicionales (por ejemplo, compresión focalizada y magnificada). Dentro de esas últimas, nombraremos a las causadas por parásitos (por

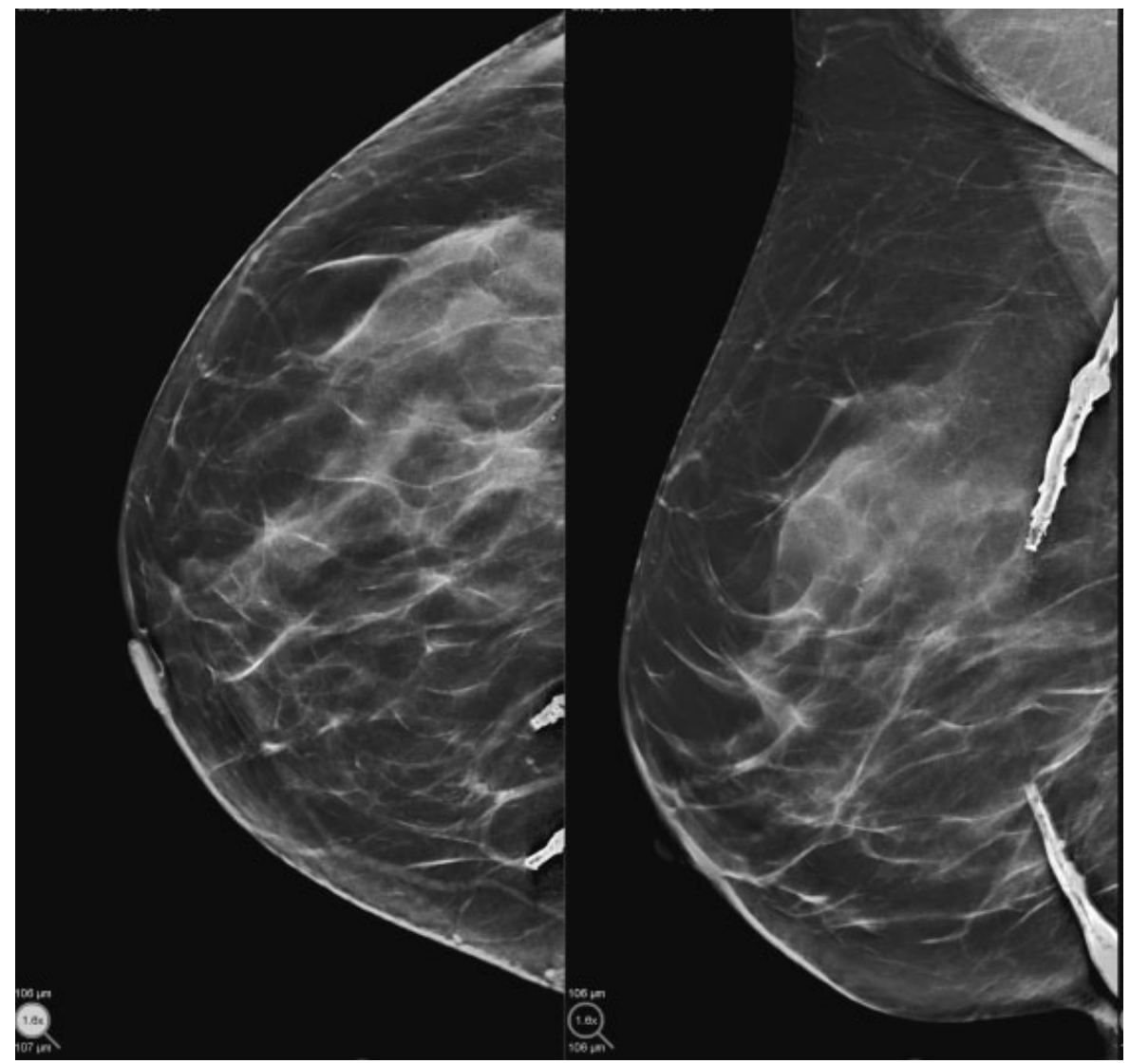

Fig. 1 Mamografía digital sintetizada. Incidencias en craneocaudal (CC) y mediolateral oblicua (MLO) de mama derecha se evidencian calcificaciones gruesas lineales discontinuas en el plano posterior de los cuadrantes internos.

received

November 17, 2017

accepted

March 12, 2018

published online

May 18, 2018
DOI https://doi.org/

$10.1055 / \mathrm{s}-0038-1642617$. ISSN 1852-9992.
Copyright $\odot$ 2019, Sociedad Argentina de Radiología. Publicado por Thieme Revinter Publicações Ltda., Rio de Janeiro, Brazil. Todos los derechos reservados.
License terms

(c) $\oplus \ominus \$$ 


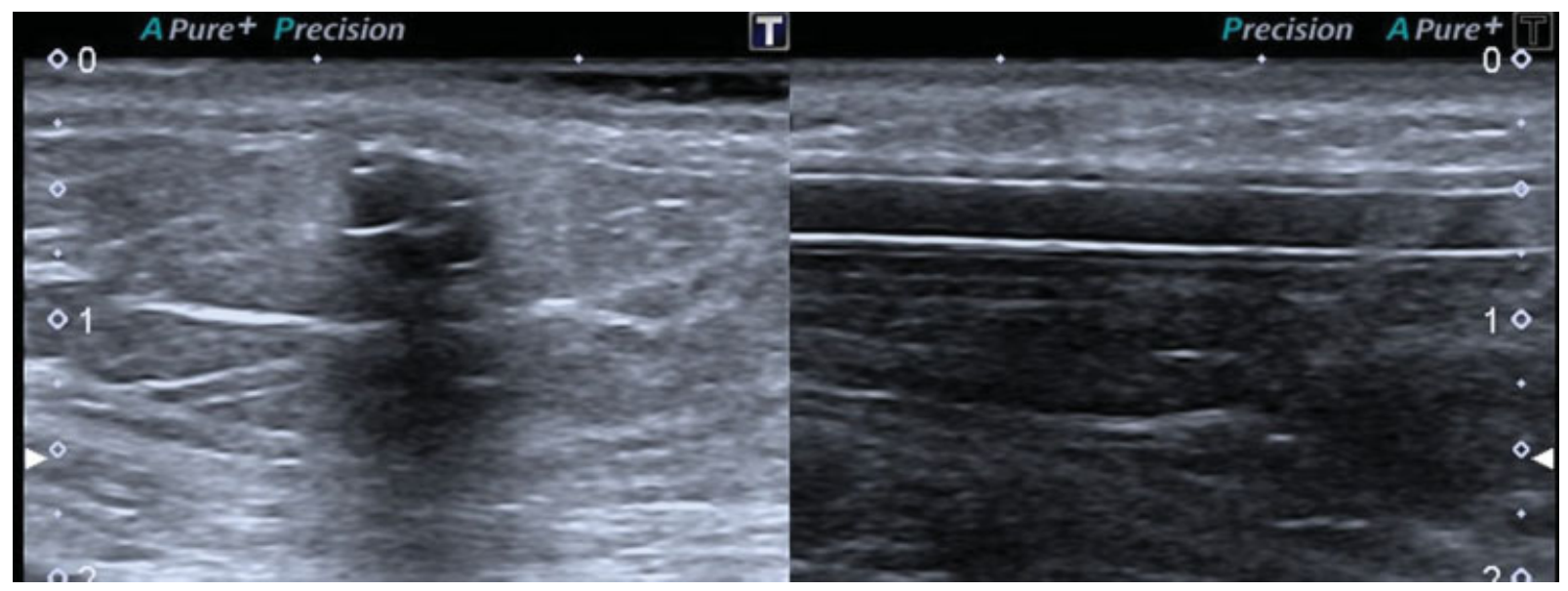

Fig. 2 Ecografía focalizada de los cuadrantes internos de la mama derecha, donde se visualiza una imagen de aspecto tubular.

ejemplo, la filariasis), por enfermedades autoinmunes (como lo son la dermatomiositis, amiloidosis), y secuelares infrecuentes (de elementos quirúrgicos). Hay que tener en cuenta que esas últimas no siempre calcifican., ${ }^{1,2}$

Se comunica un caso de una paciente de sexo femenino de 59 años de edad que fue sometida a la realización del estudio mamográfico de cribado anual, con las incidencias habituales cráneo-caudal y oblicuo-medio-lateral bilaterales. Se trató de una mama con áreas dispersas de densidad fibroglandular, en la cual se observaron calcificaciones gruesas de disposición lineal en la mama derecha proyectadas en el plano glandular profundo de los cuadrantes internos, con una solución de continuidad en el sector medio (-Fig. 1). Se recogieron los antecedentes clínico-ginecológicos de la misma, quien refirió la presencia de una válvula de derivación ventrículo peritoneal como tratamiento de una hidrocefalia de origen congénito. Posteriormente se realizó ecografía focalizada constatándose la presencia de imágenes de aspecto tubular continua con calcificaciones anulares (-Fig. 2).

El líquido cefalorraquídeo (LCR) circula por el sistema nervioso central, cumpliendo tres funciones: como amortiguador del cerebro, transportador de nutrientes, y compensador de presiones. La hidrocefalia resulta de la acumulación excesiva de LCR en el sistema ventricular, con su consiguiente dilatación. La misma ocasiona una presión potencialmente perjudicial en el parénquima cerebral. El equilibrio entre la producción y la absorción de líquido cerebroespinal es fundamental. En condiciones normales es absorbido en el torrente circulatorio a medida que circula. Las causas que condicionan su acumulación son: congénitas, adquiridas, comunicantes, obstructivas y hemorrágicas, con presión normal. El tratamiento se realiza mediante la colocación quirúrgica de un sistema de derivación que desvía el flujo del LCR del sistema nervioso central a otra zona del cuerpo donde pueda ser absorbido como parte del proceso circulatorio (cavidad peritoneal, más frecuentemente, atrial derecha, o pleural). El material consta de un tubo silástico flexible, un catéter y una válvula unidireccional. Un extremo del catéter se coloca en el sistema nervioso y el otro extremo dentro de la cavidad seleccionada. Los sistemas de derivación pueden sufrir complicaciones: falla mecánica (desconexión, obstrucción y fractura), infecciones, drenaje excesivo o insuficiente, dolor en los músculos del cuello o los hombros y enrojecimiento o sensibilidad a lo largo del conducto de derivación. Con el tiempo, puede degradarse, debido a una reacción granulomatosa, hecho que se manifiesta por la presencia de pequeñas calcificaciones circundantes. También puede interrumpirse en cualquier sitio de su trayecto, debido al crecimiento del paciente. ${ }^{3-5}$

Es importante conocer las calcificaciones benignas de origen infrecuente para una correcta categorización y recomendación. En el caso presentado de calcificación secuelar de válvula de derivación ventrículo-peritoneal calcificada, la anamnesis y análisis de las imágenes nos permitieron su adecuada categorización sin necesidad de exámenes adicionales.

Los saludan a ustedes, con distinguida consideración,

Ivelís M. Sarachi, María del R. Cepedal

\section{Responsabilidades Éticas}

Protección de personas y animales. Los autores declaran que para esta investigación no se han realizado experimentos en seres humanos ni en animales.

Confidencialidad de los datos. Los autores declaran que en este artículo no aparecen datos de pacientes.

Derecho a la privacidad y consentimiento informado. Los autores declaran que en este artículo no aparecen datos de pacientes.

Confidencialidad de los Datos

Los autores declaran que han seguido los protocolos de su centro de trabajo sobre la publicación de datos de pacientes y que todos los pacientes incluidos en el estudio han recibido información suficiente y han dado su consentimiento informado por escrito para participar en dicho estudio.

Conflicto de Intereses

Los autores declaran no tener ningún conflicto de intereses 


\section{Bibliografía}

1 Yang WT. Unusual Infections. En: Berg WA, Yang WT. Salt Lake City: Amirsys; 2014:48-51

2 Yang WT. Amyloid. En: Berg WA, Yang WT. Salt Lake City: Amirsys; 2014:72-75

3 Fernandes de Oliveira M, Muralho Pereira R, Gomes Pinto F. Updating technology of shunt valves. MedicalExpress (São Paulo) 2014;1(04):166-169
4 Gómez López L, Luaces Cubells C, Costa Clará J, et al. Complicaciones de las válvulas de derivación de líquido cefalorraquídeo. An Esp Pediatr 1997:368-370

5 Méndez AC, Taboada Ruíz MS, Michavila N, Rodríguez E, Auad RM. Diferentes complicaciones de los sistemas de derivación ventriculoperitoneal. Rev Argent Radiol 2006;70(01):11-17 